\title{
A Comparison of Panic Disorder and Agoraphobia With Panic Attacks
}

\author{
Bruce A. Thyer, Joseph Himle, George C. Curtis, Oliver G. Cameron, and \\ Randolph M. Nesse
}

The validity of distinguishing between the diagnoses of panic disorder and agoraphobia with panic attacks was examined in a study of 20 patients with each disorder. Comparison of demographic. psychometric, and clinical features of the two groups revealed few differences. Agoraphobics scored higher on ratings of interpersonal sensitivity, phobic anxiety, paranoid ideation, and alcohol use. Panic disorder patients more frequently reported periods of remissions from anxiety symptomatology. These results support the validity of conceptualizing agoraphobia with panic attacks and panic disorder as subcategories of a core endogenous anxiety disorder.

$T^{1}$ HE CURRENT anxiety disorder nomenclature found in DSM-III ${ }^{1}$ contains a striking number of changes from its predecessor, DSM-II. ${ }^{2}$ Some of the earlier diagnoses have been more clearly delineated, based on refinements in descriptive pathology or advances in etiological understanding. For example, phobic neuroses is now broken down into simple and social phobia, and agora-phobia. Agoraphobia has been subdivided into two separate syndromes with presumably disparate etiologies, agoraphobia with panic attacks, and agoraphobia without panic attacks. Anxiety neuroses contains the remaining disorders, including panic disorder and generalized anxiety disorder, again with presumably different etiologies. The diagnosis of obsessive-compulsive disorder has remained largely intact and with it a new entity, posttraumatic stress disorder, are now contained with the broader category of anxiety neuroses. Interrater reliabilities in diagnosing these DSM-III anxiety disorders, as an overall class, appear to be within acceptable, although moderate, limits. ${ }^{1}$ Recent etiological studies have partially supported the current nomenclature, at least in terms of distinguishing simple and social phobias from the other conditions. Large group studies of simple and social phobics suggest that direct or vicarious trauma may account for the majority of such patients, ${ }^{3,4}$ and histograms plotting the ages of onset for these disorders take the form of an extremely negatively skewed curve, with a preponderance of cases appearing prior to the third decade. ${ }^{5-8}$ In contrast, agoraphobic patients do not associate the onset of their disorder with traumatic experiences in public places, ${ }^{9} \cdot 10$ but more typically report the development of agoraphobia fears following the onset of repeated episodes of apparently spontaneous panic attacks. ${ }^{11-14}$ Interestingly, this mode of onset was first commented on by Freud who noted that, "In the case of agoraphobia, etc., we often find the recollection of an anxiety attack; and what the patient fears is the occurrence of such an attack under the special conditions in which he believes he cannot escape it."15

Subsequent investigations have supported the view that agoraphobia is a complication of panic attacks, as does our own experience: Of 115 agoraphobics seeking

From the University of Michigan Medical School, Ann Arbor.

Address reprint requests to George C. Curtis, M.D., Department of Psychiatry, Box 011, the University of Michigan Medical School, Ann Arbor, MI 48109.

(C) 1985 by Grune \& Stratton, Inc.

$0010-440 X / 85 / 2602-0012 \$ 03.00 / 0$ 
treatment at our clinic, $95(83 \%)$ met the diagnostic criteria for agoraphobia with panic attacks, with the remaining 20 cases $(17 \%)$ presenting as agoraphobia without panic attacks. This latter group often suffered from some somatic ailment of an unpredictable or spasmodic nature, such as epilepsy or colitis. This physical illness often served as the functional equivalent to panic attacks in terms of developing agoraphobic restrictions. See also the work by Pinto ${ }^{16}$ and Mittan ${ }^{17}$ in support of this view.

Histograms plotting the ages of onset for the conditions of agoraphobia with panic attack and panic disorder appear virtually identical, as unimodal normal curves with an average age of onset of about age 26.,19 This supports the separation of simple and social phobics from agoraphobia with panic attacks and panic disorder but challenges the distinction between panic disorder and agoraphobia with panic attacks.

Pharmacological responses also serve to distinguish patients with simple and social phobic disorders from patients with agoraphobia with panic attacks or panic disorder. Spontaneous panic attacks, unlike phobic anxiety, can be effectively treated with a variety of psychotropic compounds including the tricyclic antidepressants, ${ }^{11,13,18}$ monoamine oxidase inhibitors, ${ }^{14}$ and the triazolobenzodiazepine alprazolam. ${ }^{20.21}$ Compounds found clinically useful in suppressing spontaneous panic attacks also appear to protect against panic attacks provoked by infusions of sodium lactate $^{22}$ in the laboratory setting. Unlike phobic disorders, such as simple and social phobia, the diagnoses of agoraphobia and panic disorder appear to have a strong heritable component ${ }^{23-28}$ and are significantly associated with the cardiac anomalies of mitral valve prolapse syndrome..$^{29,30}$

A clear case can apparently be made to distinguish simple and social phobias from the subset of anxiety disorders associated with spontaneous panic attackspanic disorder and agoraphobia with panic attacks. Is there justification, however, for distinguishing agoraphobia with panic attacks, panic disorder, and generalized anxiety disorder from each other. Raskin et al. ${ }^{31}$ report that patients diagnosed as having generalized anxiety disorder or panic disorder differ in that the panic patients had an increased likelihood of a grossly disturbed childhood environment and a greater frequency of a concurrent affective disorder. Child or adult separation trauma was not found to distinguish the two groups contrary to the statement in the DSM-III. Hoehn-Saric ${ }^{32}$ failed to find differentially predisposing factors between groups of panic disorder and generalized anxiety disorder patients, although the panic disorder patients presented with more somatic symptoms. Thyer and associates $^{33}$ obtained retrospective reports of childhood separation trauma from two patient groups, agoraphobia with panic attacks $(\mathrm{N}=44)$ and simple phobia $(\mathrm{N}=83)$. In neither group did separation trauma appear particularly salient as an important predisposing factor, and, contrary to the widely accepted hypothesis of the DSM-III' ${ }^{1}$ and Klein, ${ }^{11,12}$ agoraphobics did not report a more frequent history of childhood separation trauma on any of 14 distinct forms of separation experiences investigated. Anderson et al. ${ }^{34}$ recently compared panic disorder patients $(\mathrm{N}=48)$ with patients with generalized anxiety disorder $(\mathrm{N}=18)$ on a number of selected symptomatic, demographic, personality, and etiological factors. Panic disorder patients were found to be more severe in terms of presenting autonomic symptoms. Panic disorder patients reported a rapid onset of symptoms more frequently than 
did generalized anxiety disorder patients, but there were no apparent personality differences between the two groups. The prognosis for generalized anxiety disorder seemed somewhat more favorable. Anderson et al. felt that their results supported the DSM-III distinction between generalized anxiety disorder and panic disorder.

The current study examines a variety of demographic, etiologic, and psychometric factors in patients with either panic disorder or agoraphobia with panic attacks. It was hypothesized that if these two conditions are different psychiatric syndromes, the differences between the groups should be apparent on the variables measured.

\section{MATERIALS AND METHODS}

Subjects were randomly selected from patient files at the University of Michigan Hospitals Anxiety Disorders Program. Twenty patients with the DSM-III diagnosis of agoraphobia with panic attacks and 20 patients with panic disorder were chosen, each sample consisting of 10 men and 10 women. Diagnoses had been made by a faculty clinician skilled in the use of the DSM-III criteria, including Axes IV and V, based on a 1-1/2- to 2-hour interview with each patient. Each patient had also completed an evaluation packet containing demographic, personal, family, and medical history questionnaires, the Spielberger State-Trait Anxiety Inventory, ${ }^{35}$ the Derogatis SCL-90-R, ${ }^{36}$ and the Wolpe-Lang Fear Survey Schedule. ${ }^{37}$ Subjects were selected from a pool of approximately 200 agoraphobics or panic disorder patients seen at our clinic between 1979 and early 1984. The sample consisted of 37 Caucasians, two blacks, and one Hispanic. Chi-square tests were used for tests of significance on frequency data, and the Students t-test was used to test the significance of differences on continuous variables.

\section{RESULTS}

Few statistically significant differences were found between the two patient groups. Table 1 displays patient responses to all continuously scaled variables. The two diagnostic groups differed on only three of 20 factors, each of which was a subscale of the SCL-90-R: interpersonal sensitivity, phobic anxiety, and paranoid ideation. In each instance, the agoraphobic group was found to score higher. Differences in state and trait anxiety levels, total fear survey schedule scores, ages of onset and at intake, duration of illness, level of phobic symptomatology, or clinical ratings on the DSM-III Axes 4 and 5 all did not exceed chance expectations. A number of frequency variables were examined including occupational level, marital status, tobacco use, religious preference, medication use, panic attack frequency, and types of previous psychiatric treatment. Only two significant findings emerged (see Table 2). Agoraphobic patients reported a greater use of alcoholic beverages than did the panic disorder patients, whereas panic disorder patients reported a greater frequency of periods of remission in their disorder.

There were no differences between male and female patients on any of the variables.

\section{DISCUSSION}

Our overall impression from this data is that few if any meaningful differences exist between patients diagnosed as agoraphobia with panic attacks or as panic disorder. The finding that agoraphobics score higher on the Phobic Anxiety subscale of the SCL-90-R is not surprising since this scale may be considered almost synonymous with agoraphobia, consisting of items such as "feeling afraid in open spaces or on the street," "feeling afraid to go out of your house alone," "feeling afraid to travel on buses, subways, or trains," etc. 
Table 1. Scores of Patients With Panic Disorder or Agoraphobla With Panic Attacks on Clinical and Psychometric Measures

\begin{tabular}{|c|c|c|c|c|}
\hline \multirow[b]{2}{*}{ Measure } & \multicolumn{2}{|c|}{ Panic Disorder } & \multicolumn{2}{|c|}{$\begin{array}{l}\text { Agoraphobia With } \\
\text { Panic Attacks }\end{array}$} \\
\hline & Mean & SD & Mean & SD \\
\hline Age of intake & 37.5 & 9.5 & 36.1 & 9.7 \\
\hline Age of onset & 25.9 & 8.8 & 26.3 & 10.7 \\
\hline Duration of disorder & 11.6 & 13.4 & 9.6 & 7.6 \\
\hline State anxiety & 48.9 & 14.3 & 51.1 & 15.9 \\
\hline Trait anxiety & 51.7 & 8.3 & 56.0 & 10.6 \\
\hline Total fear survey score & 106.9 & 57.1 & 122.0 & 56.6 \\
\hline Axis IV rating & 3.5 & 1.5 & 3.8 & 1.4 \\
\hline $\begin{array}{l}\text { Axis } V \text { rating } \\
\text { SCL-90-R Scores }\end{array}$ & 3.7 & 1.0 & 4.3 & 1.1 \\
\hline Somatization & 1.35 & .80 & 1.29 & .71 \\
\hline Obsessive-compulsive & 1.33 & .67 & 1.49 & .85 \\
\hline Interpersonal sensitivity & 1.35 & .70 & 1.98 & .94 \\
\hline Depression & 1.83 & .72 & 1.91 & .78 \\
\hline Anxiety & 2.02 & .81 & 2.08 & .66 \\
\hline Hostility & 1.01 & .81 & 1.55 & 1.05 \\
\hline Phobic anxiety & 1.17 & .62 & 2.42 & $.91^{+}$ \\
\hline Paranoid ideation & .75 & .73 & 1.41 & .84 \\
\hline Psychoticism & .99 & .57 & 1.05 & .74 \\
\hline Additional items & 12.00 & 5.12 & 10.55 & 6.55 \\
\hline $\begin{array}{l}\text { Positive symptom distress in- } \\
\text { dex }\end{array}$ & 2.25 & 66 & 2.27 & .48 \\
\hline
\end{tabular}

${ }^{*} P=.02$ (t-test).

$+P<.001$ (t-test)

$: P=.01$ (t-test)

The agoraphobics' higher scores on interpersonal sensitivity and paranoid ideation deserve further investigation. Given that both panic disorder and agoraphobia with panic attacks appear to have their origins in spontaneous attacks of panic, perhaps those individuals more conscious of embarrassment, humiliation, or scrutiny by

Table 2. Agoraphobic and Panic Disorder Patients Self-Rating of Alcohol Use and Occurrence of Remissions of Anxiety

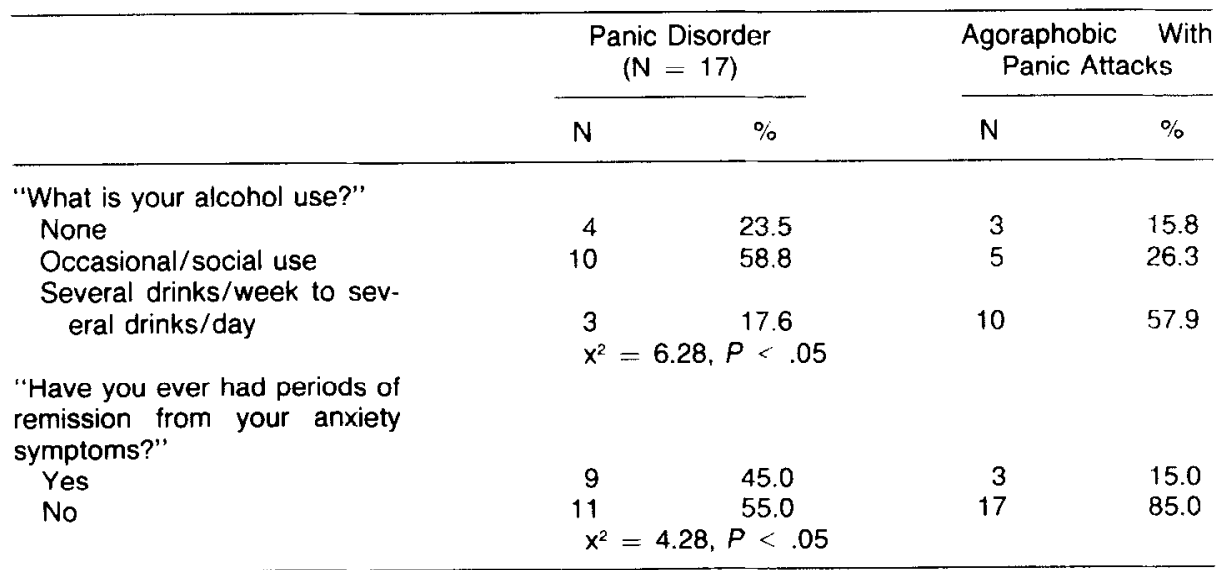


others develop the phobic restrictions of agoraphobia, while those less sensitive do not; hence, the latter are eventually diagnosed as having only panic disorder.

Other studies have suggested that agoraphobic patients are at risk for developing alcohol abuse. ${ }^{38.39}$ Why they should report greater alcohol use relative to panic disorder patients is unclear, although the hypothesis that excessive alcohol use results from attempts at self-medication of phobic anxiety is an intuitively appealing one.

Our finding that the panic disorder patients more frequently reported periods of remissions in their symptomatology compared to the agoraphobics is also of interest - such periods of remission may protect patients from developing the fullblown agoraphobic disorder. These speculations need to be considered in light of the large number of statistical analyses performed and the relative paucity of statistically significant findings observed. Accordingly, our results may at best be conservatively viewed as post-hoc hypotheses worthy of future prospective inquiry.

Recently, Sheehan ${ }^{5.14,43}$ has suggested that the anxiety disorders should be classified into two major subcategories, exogenous anxiety corresponding to simple and social phobia, and endogenous anxiety characterized by spontaneous attacks of panic, or chronic generalized anxiety. Etiologically, these two categories differ with exogenous anxiety being psychosocially based, and endogenous anxiety having a genetic biochemical core. In particular, Sheehan specifically postulates that the spontaneous panic attacks characteristic of panic disorder form the basis for an entire spectrum of clinical phenomena associated with anxiety. In the early stages of endogenous anxiety, through associative learning, spontaneous panic attacks cause the individual to develop monosymptomatic phobias or hypochondriacal concerns. If unabated, over time the spontaneous panic attacks may evolve into generalized anxiety disorder, panic disorder, or, at the end point of the progression, agoraphobia with panic attacks. Our data support Sheehan's notion of only one core condition, spontaneous panic attacks, which incorporates the disorders of panic disorder and agoraphobia with panic attacks. Similarities in clinical features include response to pharmacological treatment, ${ }^{11-14,18,20}$ susceptibility to lactateinduced panic attacks, ${ }^{40-42}$ apparent genetic component, ${ }^{23-28}$ and association with mitral valve prolapse..$^{29,30}$ We find that these two diagnoses are virtually indistinguishable on a wide variety of psychometric and etiological measures. Except for the extent of phobic impairment, the validity of agoraphobia with panic attack and panic disorder as separate entities is not supported by our data. These observations suggest that panic disorder and agoraphobia with panic attacks are not separate entities, but are slightly different presentations of a broader disorder. Further work is needed to explain why some panic disorder patients develop agoraphobia and others do not.

\section{REFERENCES}

1. American Psychiatric Association: Diagnostic and Statistical Manual of Mental Disorders (Third Ed). APA, Washington, DC, 1980

2. American Psychiatric Association: Diagnostic and Statistical Manual of Mental Disorders (Second Ed). APA, Washington, DC, 1968

3. Wolpe J: The dichotomy between classical conditioning and cognitively learned anxiety J Behav Ther Exp Psychiatry 12:35-42, 1981

4. Ost L, Hugdahl K: Acquistion of phobias and anxiety response patterns in clinical 
patients. Behav Res Ther 19:439-447, 1981

5. Sheehan DV, Sheehan KE, Minichiello WE: Age of onset of phobic disorders: A reevaluation. Compr Psychiat 22:544-553, 1981

6. Jersild AT, Holmes FB: Children's fears. Child Develop Monogr, No. 20, 1935

7. Marks IM: Fears and Phobias. Academic Press, New York, 1969

8. Marks IM, Gelder MG: Different ages on onset in varieties of phobias. Am J Psychiat 123:218-221, 1966

9. Thorpe G, Burns L: The Agoraphobic Syndrome. John Wiley, Chichester, 1983

10. Tearnan BH, Telch MJ, Keefe P: Etiology and onset of agoraphobia: A critical review. Compr Psychiatry 25:51-62, 1984

11. Klein DF: Delineation of two drug responsive anxiety syndromes. Psychopharmacologia 5:397-408, 1964

12. Mendel JGC, Klein DF: Anxiety attacks with subsequent agoraphobia. Compr Psychiat 10:190-195, 1969

13. Zitrin C, Klein DF, Woerner M, et al: Treatment of phobias, I. Comparison of imipramine hydrochloride and placebo. Arch Gen Psychiatry 40:125-138, 1983

14. Sheehan DV, Ballenger J, Jacobson G: The treatment of endogenous anxiety with phobic, hysterical, and hypochondriacal symptoms. Arch Gen Psychiat 37:51-59, 1980

15. Freud S: Obsessions and compulsions, in Strachey J (ed): The Standard Edition of the Psychological Works of Sigmund Freud, Vol. 3. Hogarth Press, London, 1962, p 81

16. Pinto R: A case of movement epilepsy with agoraphobia treated successfully by flooding. Brit J Psychiat 121:287-288, 1972

17. Mittan RJ: Patients' fears about seizures: a greater psychosocial stress? Paper presented at the International Epilepsy Symposium, Washington, DC, 1983

18. Rifkin A: Panic disorder: Response to sodium lactate and treatment with antidepressants. Psychopharmacology Bull 19:432-434, 1983

19. Thyer BA, Parrish RT, Curtis GC, et al: Ages of onset of DSM-III Anxiety Disorders Compr Psychiatry (in press)

20. Chouinard G, Annable L, Fontaine R, et al: Alprazolam in the treatment of generalized anxiety and panic disorders: A double blind placebo-controlled study. Psychopharmacology 77:229-233, 1982

21. Sheehan DV, Coleman JH, Greenblatt DJ, et al: Some biochemical correlates of panic attacks with agoraphobia and their response to a new treatment. J Clin Psychopharmacology $4: 66-75,1984$

22. Rifkin A, Klein DF, Dillon D, et al: Blockade by imipramine or desipramine of panic induced by sodium lactate. Am J Psychiatry 138:676-678, 1981

23. Harris E, Noyes R, Crowe RR, et al: Family study of agoraphobics. Arch Gen Psychiatry 40:1061-1064, 1983

24. Crowe RR, Noyes R, Pauls D, et al: A family study of panic disorder. Arch Gen Psychiatry 40:1065-1069, 1983

25. Togerson S: Genetic factors in anxiety disorders. Arch Gen Psychiatry 40:1085-1089, 1983

26. Pauls DL, Bucher KD, Crowe RR, et al: A genetic study of panic disorder pedigrees Am J Hum Gen 32:639-644, 1980

27. Pauls DL, Noyes R, Crowe RR: The familial prevalence in second degree relatives of patients with anxiety neurosis (panic disorder). J Affect Dis 1:279-285, 1979

28. Crowe RR, Pauls DL, Slyman DJ, et al: A genetic study of anxiety neurosis. Arch Gen Psychiatry 37:77-79, 1980

29. Kantor JS, Zitrin CM, Zeldis SM: Mitral valve prolapse syndrome in agoraphobic patients. Am J Psych 137:467-469, 1980

30. Venkatesh A, Pauls $D$, Crowe $R$, et al: Mitral valve prolapse in anxiety neurosis (panic attacks). Am Heart J 100:302-305, 1980

31. Raskin M, Peeke HVS, Dickman W, et al: Panic and generalized anxiety disorder. Arch Gen Psychiatry 39:687-689, 1982

32. Hoehn-Saric R: Comparison of generalized anxiety disorder with panic disorder patients. Psychopharmacology Bull 18:104-108, 1982 
33. Thyer BA, Nesse RM, Curtis GC, et al: Agoraphobia: A test of the separation anxiety hypothesis. Behav Res Ther (in press)

34. Anderson DJ, Noyes R, Crowe RR: A comparison of panic disorder and generalized anxiety disorder. Am J. Psychiatry 141:572-575, 1984

35. Spielberger CD, Gorsuch RL, Lushene RE: STAI Manual for the State-Trait Inventory. Consulting Psychologists Press, Palo Alto, CA, 1970

36. Derogatis LR, Lipman RS, Covi L: SCL-90: An outpatient psychiatric rating scalepreliminary report. Psychopharmacology Bull 9:13-28, 1973

37. Wolpe J, Lang P: Fear Survey Schedule. Educational and Industrial Testing Service, San Diego, CA, 1969

38. Mullaney JA, Trippett CJ: Alcohol dependence and phobias: Clinical description and relevance. Brit J Psychiat 135:565-573, 1979

39. Smail P, Stockwell T, Canter S, et al: Alcohol dependence and phobic anxiety states. I. A prevalence study. Brit J Psychiat 144:53-57, 1984

40. Liebowitz M, Fyer A, Appleby I, et al: Lactate provocation of panic attacks. Psychopharmacology Bull 19:476-478, 1983

41. Kelly D, Mitchell-Heggs N, Sherman D: Anxiety and the effects of sodium lactate assessed clinically and physiologically. Br J Psychiatry 199:129-144, 1971

42. Pitts FN, McClure JN: Lactate metabolism in anxiety neurosis. New Engl $J$ Med $277: 1329-1336,1967$

43. Sheehan DV, Sheehan KE: The classification of anxiety and hysterical states. Part II. Toward a more heuristic classification. J Clin Psychopharmacology 2:386-393, 1982 